\title{
Theory of neural communication based on spatio-temporal coding
}

\author{
Myoung Won $\mathrm{Cho}^{1 *}$, Moo Young Choi ${ }^{2}$ \\ From Twentieth Annual Computational Neuroscience Meeting: CNS*2011 \\ Stockholm, Sweden. 23-28 July 2011
}

Pattern coding is a general concept for neural coding, which indicates that the objective meaning of information can be represented by spatio-temporal firing patterns of a group of neurons [1]. We introduce a feasible way through which spatio-temporal firing patterns represent complex information systematically. Provided that neural codes represent features in a vector space, neural communication channels can be characterized by independent pattern components constituting basis functions in the Hilbert space. Specific applied forms of the method, depending on the choice of basis functions, reduce to the traditional coding schemes, including rate coding, temporal coding, correlation coding, independent-spike coding, population coding, phase coding, and so on. In addition, it is suggested that the ordinary neural code in the brain might take a more elaborate form, in such a way that neural networks can send or receive complex information effectively and robustly through mutable spike trains. We discuss corresponding statistics of neural codes based on the theory. Finally, we present the scheme of a cortical module as the processing unit of communication and computation based on spatio-temporal coding. It may also be applied to modelling the stimulus-response of cortical neurons.

\section{Conclusion}

We present a theory as to how neural modules communicate with each other effectively via spatio-temporal firing patterns, and propose, based on the theory, how to phrase neural codes from observed firing patterns and how to model the stimulus-response relationship for cortical neurons.

\section{Acknowledgements}

This work was supported by NAP of Korea Research Council of Fundamental Science \& Technology and by NRF through the BSR program.

\section{Author details}

${ }^{1}$ Korea Institute for Advanced Study, Seoul 130-722, Korea. ${ }^{2}$ Department of Physics and Astronomy and Center for Theoretical Physics, Seoul National University, Seoul 151-747, Korea.

Published: 18 July 2011

\section{Reference}

1. Fujii H, Ito H, Ichinose K, Tsukada M: Dynamical cell assembly hypothesis theoretical possibility of spatio-temporal coding in the cortex. Neural Networks 1996, 9:1303-1350.

doi:10.1186/1471-2202-12-S1-P38

Cite this article as: Won Cho and Young Choi: Theory of neural communication based on spatio-temporal coding. BMC Neuroscience 2011 12(Suppl 1):P38.

* Correspondence: mwcho@kias.ac.kr

'Korea Institute for Advanced Study, Seoul 130-722, Korea

Full list of author information is available at the end of the article

Submit your next manuscript to BioMed Central and take full advantage of:

- Convenient online submission

- Thorough peer review

- No space constraints or color figure charges

- Immediate publication on acceptance

- Inclusion in PubMed, CAS, Scopus and Google Scholar

- Research which is freely available for redistribution
C Biomed Central

\section{Biomed Central}

